Linha D'Água (Online), São Paulo, v. 31, n. 1, p. 29-49 jan.-abril 2018

\title{
O ALUNO UNIVERSITÁRIO MOÇAMBICANO PL2 E OS CAMINHOS DA ESCRITA: UM TRILHO SEGURO VALE MAIS DO QUE OS DOIS QUE PUSERAM A QUIZUMBA A MANCAR
}

\section{THE MOZAMBICAN PSL UNIVERSITY STUDENT'S PATH FORWARD IN WRITING: BETTER AN EGG TODAY THAN A HEN TOMORROW}

\author{
Armando Forge Lopes* \\ Universidade Eduardo Mondlane, Maputo, Moçambique
}

\begin{abstract}
Resumo: Recorrendo a dados de corpora em dissertaç̦ẽes de doutorado em linguística concluídas recentemente na UEM, analisamse, no presente artigo, segmentos discursivos infelizes na escrita de alunos universitários moçambicanos que têm o Português como língua segunda (PL2). Discute-se, especificamente, a natureza da infelicidade discursiva quanto a engenhos retóricos (marcadores) e outros elementos idiomáticos e culturais. Assume-se que os aprendentes de uma língua, a nível avançado, devem adquirir as necessárias convenções e preferências retóricas e discursivas, para que o processamento linguístico-discursivo seja cada vez mais determinado por práticas da coesão textual e da coerência discursiva. A idiomaticidade, que é pessoalizada e idiossincrática, tem a ver com formações que são peculiares a utentes de uma determinada língua e cultura, e que são normalmente reconhecidas por escreventes nativos ou quase-nativos. Argumenta-se que 0 escrevente PL2, em média, não tem normalmente dificuldades com 0 conteúdo da mensagem, embora tenda, por vezes, a evidenciar problemas no modo como estrutura esse conteúdo. Revela também problemas de tipologia textual e idiomaticidade, quer por defeito (escrita sub-idiomática), quer por excesso (escrita sobre-idiomática), quando comparados com a escrita nativa. Para superar este tipo de problemas, entendemos que o processo de ensino-aprendizagem é melhor servido quando é centrado no aprendente.
\end{abstract}

Palavras-chave: escrita; análise do discurso; retórica; idiomaticidade; abordagens ao ensino PL2.

Abstract: Resorting to data taken out of corpora from doctoral dissertations in linguistics, which have recently been completed at the UEM, the present article analyses infelicitous discourse segments in Portuguese Second Language (PSL) writing composed by Mozambican university students. The nature of discourse infelicity related to rhetorical devices (discourse markers), and other idiomatic and cultural elements is especially discussed. It is assumed that advanced learners of a given language need to acquire the necessary conventions as well as discourse and rhetorical preferences, so that their linguistic-discursive processing is increasingly determined by the practices of textual cohesion and discourse coherence. Idiomaticity, which is personalized and idiosyncratic, has to do with formations which are peculiar to users of a determined language and culture, and which are normally recognized by its native or

* Professor Catedrático Jubilado, Universidade Eduardo Mondlane - UEM, Maputo, Moçambique; ajplopes2581950@gmail.com 
Linha D'Água (Online), São Paulo, v. 31 , n. 1, p. 29-49 jan.-abril 2018

quasi-native writers. It is argued that the average PSL writer does not normally miss the message content, although he may, at times, tend to miss the way in which the message content is structured. He equally shows problems with text typology and idiomaticity, either by default - by being under-idiomatic, or by excess - by being over-idiomatic, when compared with native writing. In order to overcome this kind of problems, we believe that the teaching-learning process is best served when it is learner-centred.

Keywords: Writing; Discourse Analysis; Rhetoric; Idiomaticity; PSL Teaching Approaches.

\section{Introdução}

O objectivo deste artigo é, por um lado, descrever e analisar segmentos discursivos considerados infelizes na escrita do aluno universitário que tem a língua portuguesa como L2 (língua segunda), a um nível avançado, no contexto plurilingue de Moçambique (Português coexistindo com as línguas bantu e outras, incluindo as de origem asiática e o Árabe) e, por outro, discutir boas práticas didácticas no âmbito do processo de ensino-aprendizagem com vista a que o aluno adquira maior sensibilidade para o melhoramento do discurso e idiomaticidade na sua escrita L2 e, por vezes, mesmo na escrita dos que têm o Português como língua quase-nativa. Sempre que oportuno, haverá comparações e referências à produção proficiente, tanto em termos da escrita bilingue (escrevente do Português e de uma língua bantu), como em termos da escrita no Português como língua materna (que em Moçambique representa cerca de 8 por cento da população total estimada em 25 milhões de cidadãos).

No presente artigo faz-se referência a um método simples para o tratamento da idiomaticidade, que usámos também em aulas de língua portuguesa. Seria talvez mais adequado chamar-lhe 'método para a aprendizagem da idiomaticidade' (e discursividade, em geral), uma vez que, como o título deste artigo sugere, o processo se centra no aluno (aprendente), e não no professor, que funciona mais como monitor, acompanhante e mobilizador. A ideia fundamental em que a discussão se baseia é que o aluno poderá estar em melhor posição para determinar que formações idiomáticas podem ser adequadamente adicionadas ao mundo da idiomaticidade que já conhece e utiliza. 
Linha D'Água (Online), São Paulo, v. 31, n. 1, p. 29-49 jan.-abril 2018

Usamos o termo formação idiomática para nos referirmos a uma realização discursiva (portanto, a nível da macrolinguística) como, por exemplo, um idiomatismo ou qualquer outra categoria idiomática. Segundo Lopes et al. (2016: 5), a linguagem idiomática tem a ver com as formações que são peculiares a uma determinada língua, que são mais ou menos fixas e que são normalmente reconhecidas por falantes ou escreventes nativos ou quase-nativos dessa língua. Exemplos de formaçôes idiomáticas são, entre outras, o ditado popular, o provérbio, o idiomatismo, as figuras de estilo, o cliché, a símile, a alusão, as co-ocorrências gémeas (incluindo colocaçôes), o eufemismo, o bordão retórico (catchprase), o slogan, o lugar-comum e a frase feita, a muleta retórica (phrase filler), a pergunta retórica, as rotinas pré-fabricadas e ritualizadas. O termo macrolinguística-por oposição ao de 'microlinguística' (enquadramento da fonologia-à-semântica)—engloba descrições de processos de comunicação e de processos sociais, cognitivos, culturais e históricos no âmbito do paradigma da análise do texto-ao-discurso.

Quanto à noção de falante não-nativo mas com domínio de língua semelhante ao do nativo, Medgyes (1994: 14-15) designa-o por pseudo-native speaker (falante pseudo-nativo). Para tal situação, preferimos a designação 'quase-nativo'. Em média, o escrevente quase-nativo não tem falhas em relação ao conteúdo da mensagem, nem em relação à forma e estrutura do que escreve. A menor capacidade macrolinguística que vários alunos revelam tem a ver com as instâncias de discurso em que a gramática e o léxico são nativos ou quase-nativos, mas as dimensões retórica e cognitiva não estão processadas adequamente; isto é, há determinadas 'coisas' que não estão mal ou não são incorrectas gramaticalmente, mas que soam estranhamente quando postas a uso.

$\mathrm{Na}$ senda de Widdowson (1978), precisamos de adquirir regras de uso formal ('language usage'), isto é, regras relacionadas com a gramaticalidade das frases e com a habilidade do falante ou escrevente em não violar regras de organização textual, e adquirir também regras de uso funcional ('language use'), isto é, regras que indicam que enunciados são apropriados a uma determinada situação comunicativa, transmitindo o que o escrevente pretende. Foi neste contexto que recorri ao trabalho magistral de Austin (1962) - e especialmente ao conceito de infelicidade e à doutrina das Infelicidades (p. 14), que criou nos domínios da filosofia da 
Linha D'Água (Online), São Paulo, v. 31, n. 1, p. 29-49 jan.-abril 2018

linguagem e da pragmática - para formular o conceito e termo de discourse infelicity ['infelicidade discursiva'] (Lopes, 1986: 2-3) e, depois, o termo de infelicidade idiomática (Lopes, 2016: 3; 2013: 129; 2004: 177;1990).

Em relação às convenções e engenhos retóricos que exprimem pensamentos, ideias e argumentos, constata-se que são específicos de uma determinada língua e cultura e que, portanto, os seus escreventes utilizam diferentes engenhos retóricos (como por exemplo, os marcadores discursivos) no âmbito do uso de diferentes funções retóricas, como a comparação, o contraste, a análise, a síntese, a expansão, a sequência lógica, e outros princípios pragmáticos como o tacto, a polidez, transparência, expressividade, clareza, economia, generosidade e a modéstia. A comunicação bem-sucedida requer do escrevente a partilha do código linguístico, das convenções retóricas e de outras dimensões não-linguísticas da experiência, incluindo o nível literário e a visão do mundo (schemata).

\section{Dados e análise}

Apresentam-se e analisam-se, de seguida, fragmentos discursivos infelizes na escrita PL2.

\section{Predição [discurso relatado] e cognição}

“...Quando chegou a casa, o pai disse ao filho que tu tens de sair daqui do mato e ir no próximo mês para um colégio em Maputo aprender essas coisas de meio ambiente..."

Em primeiro lugar, aspectos que se prendem com a problemática do discurso relatado em redacções de estudantes, em que é fundamental considerar outros factores que não meramente os gramaticais. Por exemplo, em relação a um fragmento como "...Quando chegou a casa, o pai disse ao filho que tu tens de sair daqui do mato e ir no próximo mês para um colégio em Maputo aprender essas coisas de meio ambiente...", e considerando o nível relativamente avançado de conhecimento da língua por parte do aluno universitário moçambicano que produziu tal 
Linha D'Água (Online), São Paulo, v. 31 , n. 1, p. 29-49 jan.-abril 2018

enunciado na escrita, avento a hipótese de se poder tratar de um caso em que o aluno tenha marcado (realçado), de forma talvez automatizada, uma determinada função narrativa. Reparo também que, em outras passagens da sua composição, o aluno demonstra que sabe operar mudanças pronominais ou backshifts em dois ou três segmentos em que ocorriam relatos discursivos indirectos. $\mathrm{O}$ que me parece que estava a acontecer é que em determinados momentos o aluno marcava a voz (isto é, quem fala), como sendo a voz do narrador. E quando pretendia fazer que um acontecimento passado fosse relatado como se tratasse de um acontecimento presente, um acontecimento do 'agora', o aluno marcava a voz do personagem. Muito embora ocorrências discursivas desta natureza possam também, por vezes, ocorrer na produção de escreventes quase-nativos, o maior volume e a maior frequência de ocorrências têm lugar por parte de utentes da língua como língua não-nativa. No caso destes últimos, a causa das ocorrências parece dever-se, em medida considerável, a transferências do substrato bantu, que opera a marcação desse modo. As possibilidades colocadas em relação à marcação da voz (voice markedness), no caso vertente, fazem-nos crer ser importante que na abordagem da produção do aluno se considerem não só as propriedades gramaticais, mas também e sobretudo - considerando o nível avançado - as propriedades discursivas, incluindo a mensagem que o seu produtor pretende transmitir e a sua visão do mundo, que inclui a experiência de vida. Retornarei, mais em baixo e em termos mais teóricos a esta questão do discurso relatado, uma das categorias que Tadros criou no âmbito do seu modelo da predição textual.

Em segundo lugar, há aspectos cognitivos relacionados com a escrita em que o fragmento se insere (content schemata), e em que determinada produção pode, por vezes, ser avaliada como inadequada não necessariamente por razões linguísticas e textuais, mas por motivos que se prendem com a falta de conhecimento sobre um certo tópico por parte de um dos intervenientes (aluno ou professor) neste processo, ou por motivos que se prendem com uma deficiente compreensão da consciência cultural de cada uma das partes. Para além das infelicidades discursivas que o professor registou, este considerou também que o tema 'meio ambiente e medidas sanitárias' era ilógico e que, por isso, o aluno acabou por ser penalizado na avaliação da sua composição. Reflectindo à posteriori, o que parece ter acontecido 
Linha D'Água (Online), São Paulo, v. 31, n. 1, p. 29-49 jan.-abril 2018

foi um desencontro entre as expectativas e suposições sobre o assunto por parte do professor e as expectativas e suposições por parte do aluno expressas na composição. Enquanto o professor antevia que o aluno associasse as medidas sanitárias à recolha e destino do lixo para o aterro sanitário, e o sistema de tratamento e abastecimento de água canalizada a áreas urbanas, o aluno pensava em medidas sanitárias associadas à queima do lixo junto à habitação e ao abastecimento de água a partir do poço ou, em alguns casos, a partir do fontanário, em ligação a zonas rurais. Obviamente, cada uma das partes abordava o tema com base na sua própria estrutura cognitiva e cultural. O professor pensava na cidade e o aluno pensava no campo, de onde era oriundo.

O escrevente esforça-se por se fazer entender pelo seu potencial leitor, com quem partilha conhecimento; por outro lado, o leitor serve-se de sinais que estão visíveis no texto e que envolvem instâncias de uso contextual, como expôs Widdowson (1978), quando discutia a questão da interactividade que ocorre tanto na produção como na reconstituição discursiva e textual. Esta questão atraiu a atenção de Tadros que na sua obra sobre predição (1985) explora alguns desses sinais no texto escrito, adoptando uma perspectiva interactiva, e desenvolvendo uma certa aproximação ao texto escrito a partir do oral. Para esta linguista sudanesa, a interacção, que é claramente recíproca, é convertida num processo cognitivo encoberto; o escrevente e o leitor empenham-se numa interacção em que o escrevente assume o papel de ambos, destinador e destinatário, e conduz um diálogo aberto com o seu suposto interlocutor. Para melhor situar a sua proposta de abordagem, Tadros cria os conceitos de 'predição' e de 'antecipação', definindo-os assim: a antecipação envolve suposições por parte do leitor, enquanto que a predição envolve um compromisso, em algum ponto do texto, para com a ocorrência de um outro evento linguístico subsequente. Assim, perante um dado sinal, o leitor é capaz de predizer o que o escrevente vai fazer mais adiante. Na sua teoria, Tadros (1985:27) afirma que no caso da leitura e durante a interacção discursiva com o escrevente, o leitor, por via do texto, hipotetiza, antecipando os conteúdos que se seguirão e as relações com o que foi escrito anteriormente; são seis as categorias da predição, segundo Tadros. Destas, a categoria escolhida (só uma, devido à limitação de espaço que o presente artigo impõe) para a análise da predição no fragmento infeliz, 
Linha D'Água (Online), São Paulo, v. 31, n. 1, p. 29-49 jan.-abril 2018

discutido anteriormente, foi o discurso relatado. Por fim, é necessário entender, por um lado, que a noção de predição, como tipo textual [text type] - (outros tipos são a narração, a descrição, a definição, a argumentação, a comparação, o contraste, etc.) é linguistica e discursivamente definida pelos seus aspectos sintácticos, lexicais, lógicos, retóricos e cognitivos, que intervêm na sua composição; e, por outro, que o género textual [genre], como a conversa, o bate-papo, a piada, o conto, o artigo científico, o anúncio, o romance, o mito, entre outros, constitui o invólucro que o tipo textual requer, ocorrendo, por vezes, múltiplos tipos textuais.

\section{Mudança do ponto de vista}

Por vezes, as análises são mais difíceis e mais complexas porque o analista tem de determinar se um certo traço, se certa tendência revelados no discurso constituem, de facto, ocorrências de natureza macrolinguística (i.é, discursiva) e não ocorrências resultantes de deficiências microlinguísticas (i.é, gramaticais). Num diálogo criado por um dos alunos na sua redacção, ocorre o seguinte fragmento textual:

“Eu vou ali à cozinha levar uma cadeira, estou estoirada.”, cuja intenção é Eu vou ali à cozinha buscar uma cadeira, e não transportar uma cadeira para nenhum sítio.

Como poderíamos, então, explicar esta situação? É apenas um problema microlinguístico entre 'ir levar' e 'ir buscar’? Ou será, antes, um caso cognitivamente influenciado por factores macrolinguísticos? Em minha opinião, tendo para a segunda hipótese. Verbos como 'levar' e 'trazer', 'dar' e 'receber', e 'ir' e 'vir' evocam a mesma cena, mas descrevem-na de pontos de vista diferentes. Se pegarmos, por exemplo, no par:

"A Joana vai à Beira no domingo, enquanto tem pouco dinheiro para a estadia." "A Joana vem à Beira no domingo, enquanto tem pouco dinheiro para a estadia.",

verificamos que (a) é enunciado por um falante que está localizado (ou segue a viagem de Joana) num sítio qualquer fora da Beira, normalmente mas não 
Linha D'Água (Online), São Paulo, v. 31, n. 1, p. 29-49 jan.-abril 2018

necessariamente o ponto de partida da viagem da Joana; e que (b) é enunciado por um falante que está localizado na Beira, ou para quem a Beira é o ponto a partir do qual se faz referência à viagem da Joana. Assim, tanto (a) como (b), usando os verbos de movimento ir e vir, envolvem dois pontos, a saber, origem e destino. Os verbos ir e vir 'seleccionam' como sujeito o actor cujo ponto de vista se toma em consideração. Por isso, ir, levar e dar são verbos do ponto de vista da origem, enquanto vir, receber, trazer e buscar são verbos do ponto de vista do destino. A diferença entre verbos de movimento como ir e vir, que determinam pontos de vista diferentes, encontra paralelo em levar e trazer em tanto que verbos de mudança de posse como dar e receber.

Julgamos que a marcação do destino ou a marcação da origem na mudança do ponto de vista - viewpoint switching - que é uma categoria discursiva, deve ser tomada em consideração ao analisar-se o enunciado inicial, em que ir levar é utilizado em vez de ir buscar. O verbo buscar significa (ir ao encontro de + ) trazer. E ir buscar significa: ir + ir ao encontro de + pegar + trazer. Assim, confrontamo-nos aqui com a seguinte situação invulgar: um verbo (ou dois verbos juntos) que tem como ponto de vista não só a origem, mas também o destino. $\mathrm{O}$ que aconteceu no enunciado original, "Eu vou levar uma cadeira" (está a tornar-se frequente no PM), foi que o escrevente marcou todo o evento apenas do ponto de vista da origem. Porquê? Parece-me que do ponto de vista do escrevente (que faz realizar a acção, para a frente e para trás), o evento, na sua totalidade, foi seguido como se de uma única cena se tratasse, porque foi marcado apenas através da orientação do falante no texto. Nesta perspectiva, levar fica equivalente a levar + trazer.

Quanto ao segundo segmento do fragmento (enquanto...) o que é que realmente se passa? Seguramente, esta é uma marcação discursiva do tipo PL2. O escrevente quase-nativo da língua portuguesa marcaria o discurso de outra maneira, utilizando certamente um marcador condicional concessivo/de contraste $[. .$. embora tenha...].

Para os falantes moçambicanos nativos da língua portuguesa ou quase-nativos, o marcador enquanto pode significar, 1. "durante o tempo em que" [p.ex.: Não posso ir à rua, enquanto a criança estiver a descansar.], 2. "ao mesmo tempo que" [p.ex.: Vou ao mercado enquanto vais à farmácia.], 3. “à medida que” [p.ex.: Enquanto os rapazes iam ficando, as raparigas partiam em massa.] e 4. "na qualidade 
Linha D'Água (Online), São Paulo, v. 31 , n. 1, p. 29-49 jan.-abril 2018

de" [p.ex.: Enquanto professor nesta escola, não permito brincadeiras na sala de aulas.]. Esta é uma área fundamental de investigação na retórica que é a marcação de informação, em particular os artifícios usados para esse fim e que, habitualmente, têm sido designados por marcadores discursivos. Entre os que são merecedores de atenção especial nesta categoria destacamos marcadores discursivos como: enquanto, quando, no momento em que. No que toca a marcadores condicionais concessivos e hipotéticos, poderíamos ter: embora, por mais que, no caso de, etc.

Noutras composições, deparámo-nos com fragmentos discursivos do tipo: “...Embora tenha partido a perna, prometeu estar presente na festa..." que, em função do contexto textual (cotexto), não era necessário marcar o segmento "embora...perna”, porque tal não é requerido. Naquele contexto, poder-se-ia ter optado por "Ele (ela) prometeu estar presente na festa apesar de ter partido a perna", por não haver necessidade de topicalizar o segmento "embora...perna”, atribuindo-lhe o estatuto de informação mais dinâmica (+Remática). Por outro lado, encontrei noutra composição o seguinte fragmento: “...Embora esteja a ler o vosso manual pela primeira vez, a minha irmã e eu gostámos das ideias novas sobre os passatempos que ele apresenta..."

Aqui poderíamos colocar a seguinte pergunta: há algum contraste entre ler o manual pela primeira vez e gostar do manual?

Claro que não e, por isso, o fragmento é infeliz. Se tivesse sido escrito assim - "Embora não goste de passatempos, adorei o vosso manual" - a afirmação teria tido sentido. Como está, o marcador embora foi inadequadamente seleccionado. $\mathrm{O}$ escrevente poderia ter escrito: "Falando como leitores recentes do vosso manual, a minha irmã e eu adorámos esse manual.”

Os marcadores discursivos (engenhos retóricos) operam no contexto de diferentes funções retóricas como sejam o contraste, a comparação, a dedução, a indução, a análise, a síntese, a expansão, a dúvida e certeza, a sequência lógica, etc. Para além das estratégias lógicas, existem outros factores que requerem também atenção particular como, entre outros, a atitude em relação ao tema ou tópico (ironia, envolvimento, etc.) e o propósito da escrita, ou seja, se ela serve para informar, entreter ou convencer, entre outros. Considerações deste tipo ocorrem em linha 
Linha D'Água (Online), São Paulo, v. 31 , n. 1, p. 29-49 jan.-abril 2018

idêntica de orientação investigativa seguida por Marquesi, Elias e Cabral (2017) a propósito de planos de texto e sequências textual.

\section{Idiomaticidade}

O idiomatismo é definido como uma formação que transmite um significado metafórico, decorrendo este significado da comparação de uma coisa ou pessoa com outra, e em que se especifica que a primeira é a segunda, como no exemplo Ela foi uma fera nos debates. $\mathrm{O}$ idiomatismo acrescenta cor e frescura à escrita, tornando-a mais interessante, mais atraente. A idiomaticidade é pessoalizada e idiossincrática - modo comportamental ou maneira de pensar que é peculiar a um indivíduo ou grupo - e tem a ver com as formações (mais ou menos fixas) que são peculiares aos utentes de uma língua, e que são normalmente reconhecidas por escreventes nativos ou quase nativos.

Neste âmbito, ilustramos e discutimos alguns casos do PL2. Vejamos, de início, formaçôes idênticas no Português, mas diferentes no Xichangana. Encontrámos muitas co-ocorrências gémeas idiomáticas do tipo partir de armas e bagagens = murimi lwenene afambafamba ni xikomu [lit.: o bom camponês anda com a sua enxada] que, por ser formalmente muito diferente na língua bantu, observamos pelo contexto que o escrevente PL2 - que usara adequadamente a formação na língua portuguesa - não associara à forma do idiomatismo o significado apropriado de partir com todos os bens ou com todos os pertences, resultando, deste modo, num fragmento infeliz. Por outro lado, outro escrevente que pretendia utilizar, em contexto de perigosidade, o idiomatismo pôr o guizo ao gato, revelou não o compreender bem, porque o que fez foi construir uma expressão infeliz na forma, 'extrair os dentes ao gato', o que não faz sentido. Isto é, o aluno revela conhecer o significado do idiomatismo que tenciona utilizar (colocar-se em situação perigosa/realizar uma tarefa difícil, com grande risco pessoal, visando enfraquecer o inimigo, etc.), mas fatha na execução formal porque transfere negativamente (traduzindo, por decalque, para a L2) o idiomatismo da sua língua materna, o Xichangana: kususa matinyo ya ngwenya [lit.: extrair os dentes ao crocodilo]. Funcionalmente, o idiomatismo está bem, mas formalmente não! (este é um caso contrário ao de cima). 
Linha D'Água (Online), São Paulo, v. 31, n. 1, p. 29-49 jan.-abril 2018

O idiomatismo é uma combinação de palavras que tem um significado peculiar que não pode ser deduzido das suas partes e que, por essa razão, pode, por vezes, parecer ser algo completamente ilógico e absurdo, devido a esse fosso entre o significado literal dos constituintes individuais do idiomatismo e o significado do todo idiomático.

Neste contexto e recorrendo a abordagens mitológicas e religiosas, Kitoko -Nsiku (2007), revisita o mito e a sabedoria constantes da passagem no livro de Génesis referente à tentação (Génesis: 3) e sugere que em vez do método alegórico - que significa outro, diferente - da polarização (Deus-Diabo, pecado-perdão, homem-mulher), se utilize o método tautegórico para a abordar e interpretar a tríade Deus, mulher e serpente como símbolos que interagem entre si e que, segundo este académico congolês, representam as mesmas coisas (tauta), o que "significa, por um lado, que Deus paradoxalmente oculta e revela a sabedoria da mulher e da serpente e que, pelo mesmo simbolismo, a mulher e a serpente também ocultam e revelam a sabedoria de Deus."1

\section{Metodologia no processo de ensino-aprendizagem da idiomaticidade}

\section{Porquê, então, a centralidade no aprendente?}

Não pode ser o professor nem aquele que elabora o programa quem toma, de forma exclusiva, as decisões sobre o que fazer com a idiomaticidade numa sala de aulas. $\mathrm{O}$ aprendente deve ter uma palavra no processo de ensino-aprendizagem, devendo poder escolher o que está a aprender e o modo como aprende. É claro que isto não significa que o professor desapareça da sala de aulas, devendo com autoridade criar as condições requeridas para que o processo de aprendizagem ocorra, fornecer os sinais iniciais, monitorar e conduzir o processo. Como há prós e contras em cada método, pode-se aprender muito de abordagens convencionais e de abordagens menos convencionais, que se baseiam na experiência individual e particular do professor, em termos do que ensina e como o faz, e do aluno, no

1 This means that in one hand, God paradoxically occults and reveals woman and serpent wisdom and by the same token woman and serpent also occult and reveal God's wisdom. 
Linha D'Água (Online), São Paulo, v. 31 , n. 1, p. 29-49 jan.-abril 2018

modo como aprende. $O$ processo de ensino-aprendizagem ganha certamente muito mais com achegas diversas por parte dos intervenientes, como Lopes (1997:62) refere a este propósito: "O método de ensino global deve ser ecléctico, devendo-se tentar sempre utilizar qualquer dos métodos disponíveis, de acordo com as circunstâncias específicas." Incluem-se naturalmente métodos mais recentes como o CALL, acrónimo de "Computer-Assisted Language Learning" [aprendizagem de uma língua com o apoio de um computador], em que o ensino e a aprendizagem de línguas são feitos mediante o uso de tecnologia informática e da Internet. A vantagem do $C A L L$ é a interactividade, no uso individual e no uso colaborativo de programas (SANTOS, 2003).

\section{O conceito de formações idiomáticas fronteiriças}

A nossa preocupação reiterando o enfoque no aprendente no que toca à sua aquisição da idiomaticidade, gerando as formações de que precisa e utiliza, tem a ver com o facto de notar que a proficiência linguístico-discursiva se tem deteriorado nos últimos anos, coincidindo com processos de ensino-aprendizagem que desvalorizam, cada vez mais, o enfoque metodológico centrado no aprendente, como acontecia há três décadas. É claro que há outros factores que explicam o declínio, como, por exemplo, a crise na qualidade da educação que infelizmente se foi instalando no país.

O conceito de formações idiomáticas fronteiriças é muito simples na forma como o concebemos: há um caminho que nos leva ao trilho (o da esquerda) das formações que o aluno conhece e utiliza na sua escrita com facilidade (trilho das formações idiomáticas conhecidas); e ao trilho (o da direita) das formações de que nunca ouviu falar nem viu em texto escrito (trilho das formações idiomáticas desconhecidas). O caminho (Fig.1) que leva a estes trilhos, chamado de caminho de garfo, é um caminho que se bifurca, que se divide em dois trilhos a partir de certo ponto desse caminho. Entre o trilho das formações conhecidas e o trilho das formações desconhecidas existe um espaço que é um espaço intermediário, onde há muitas formações idiomáticas fronteiriças que o aprendente não reconhece totalmente, que só as compreende em parte ou só as utiliza de modo hesitante. 
Linha D'Água (Online), São Paulo, v. 31, n. 1, p. 29-49 jan.-abril 2018

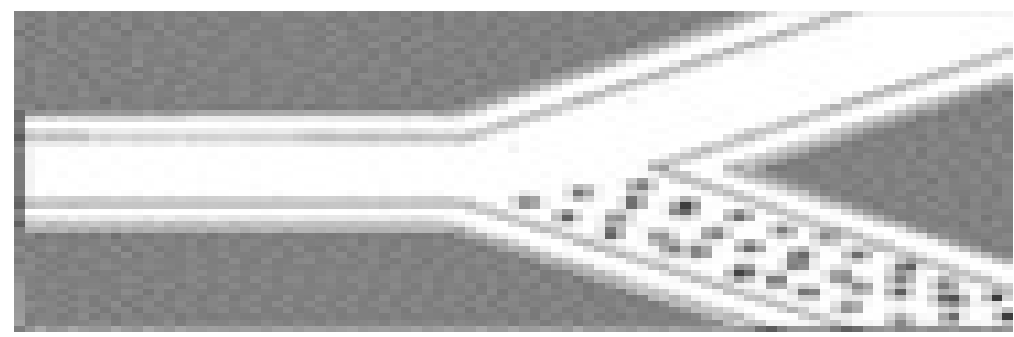

Figura 1

A diferença entre o trilho das formações conhecidas e o espaço intermediário é, de algum modo, semelhante à diferença entre o conhecimento activo (produtivo - que se produz) e o conhecimento passivo (receptivo - que se recebe): referirmonos ao trilho das formações conhecidas é quase a mesma coisa que nos referirmos ao trilho em que as formações estão activas, e ao mesmo tempo referir que o espaço intermediário contém formações que só são reconhecidas ou compreendidas apenas em parte, enquanto que as formações passivas são totalmente compreendidas, mas não utilizadas activamente. As formações idiomáticas fronteiriças são reconhecidas prontamente porque já foram anteriormente ouvidas ou vistas várias vezes, mas o seu significado ainda não foi totalmente apreendido. Muitos alunos conhecem esse tipo de formações e são capazes de referir exemplos sem grande dificuldade. É o conhecimento parcial destas formações idiomáticas fronteiriças que dá indicações ao aprendente sobre a sua utilidade e uso num determinado contexto, levando-o a assimilá-las rapidamente. A sua utilidade resulta do facto do aluno já as ter encontrado inúmeras vezes, o que significa que essas formações exibem uma certa regularidade no seu repertório linguístico-discursivo. $\mathrm{O}$ acto de identificação de tais formações acciona as schemata (estruturas cognitivas) já existentes. Ao desenvolver a sua idiomaticidade, o aluno tenta, em nossa opinião, ir ao encontro de formações idiomáticas fronteiriças trazendo-as para a sua área de conforto que é o trilho das formaçôes idiomáticas conhecidas, resultando numa colonização idiomática.

O trilho das formaçôes idiomáticas desconhecidas contém naturalmente formações idiomáticas que podem ser potencialmente úteis para o aluno, mas inclui também muitas outras que não servem, que não têm utilidade nenhuma; e o aluno não tem maneira de distinguir entre umas e outras, devendo esperar que as formações sejam 'filtradas' ao passarem do trilho desconhecido para o espaço intermediário e 
Linha D'Água (Online), São Paulo, v. 31 , n. 1, p. 29-49 jan.-abril 2018

para, de seguida, e gradualmente, as apreender e assumir. Podemos, deste modo, e a propósito, fornecer aos alunos a seguinte imagem: o trilho das formações idiomáticas desconhecidas (o da direita, malhado), que está envolto em vegetação espessa, é o trilho que ainda não foi explorado, que está cheio de incertezas e receios - digamos, o mato que está para além da vida existente no trilho conhecido e na área adjacente aos dois trilhos. $\mathrm{O}$ aluno compreenderá facilmente o seguinte: que o trilho seguro (o das formações conhecidas) vale mais do que a opção pela adição do trilho seguro ao trilho inseguro (o das formaçôes desconhecidas) e que acabou por pôr a quizumba a mancar, porque se feriu ao querer, em simultâneo, abarcar os dois trilhos com as patas! Querer tudo e não conseguir nada: a situação em que o aluno começa a baralhar-se porque utiliza idiomatismos que ouve pela primeira vez para uso inadequado em determinados contextos, em vez de se cingir ao idiomatismo que já conhece e que sabe usar. Isto é, que as formações do trilho conhecido (seguro), assim como as formações do espaço intermediário até à fronteira com o trilho inseguro são as formações adequadas ao contexto de uso ou as que podem vir a sê-lo, enquanto que as formações desconhecidas são aquelas que se encontram no mato. $\mathrm{O}$ que o aprendente detém e que sabe que é certo não pode ser trocado pelo duvidoso, tal como no significado do idiomatismo 'mais vale um pássaro na mão que dois voando' ou 'mais vale tico-tico no prato que jacu no mato' ou ainda no Inglês, língua importante na África Austral, em que Moçambique se insere, better an egg today than a hen tomorrow [lit.: é melhor um ovo hoje do que uma galinha amanhã]/a bird in hand is worth two in the bush [lit.: um pássaro na mão vale dois no mato]. O professor intervém ajudando o aluno a operar selecções que o conduzem ao limite fronteiriço, não ao mato do desconhecimento.

Conta-se a história de que uma quizumba (hiena) seguia por um caminho perseguindo dois cabritos para os matar, mas que chegados a uma bifurcação, cada cabrito seguiu o seu trilho diferente. Ambiciosa, ao colocar as patas do lado esquerdo no trilho à esquerda e as patas do lado direito no trilho à direita, a hiena quebra a anca, estatela-se e desconjunta-se. Moral da história: A quizumba só devia ter seguido por um caminho (o seguro e sem obstáculos) e caçado apenas um cabrito, pois querendo caçar os dois, não só os perdeu como se feriu; daí o idiomatismo no PM 'Um trilho seguro vale mais do que os dois que puseram a quizumba 
Linha D'Água (Online), São Paulo, v. 31, n. 1, p. 29-49 jan.-abril 2018

a mancar', por via do Xichangana [língua bantu que em Maputo é mais falada, juntamente com o Xirhonga (Lopes, 2001)]:2 'Mhisi (hiena) ya (de) mikoka (pegadas) yimbiri (duas) yisuleka (faz desconjuntar) nyonga (a anca)'.

\section{Uma prática para a aquisição da idiomaticidade}

Propomos que se coloquem formações fronteiriças em fichas da seguinte forma: na parte da frente da ficha escreve-se a formação idiomática fronteiriça com todo o contexto textual em que se localiza e sublinha-se a formação; na parte de trás da ficha (no verso) escreve-se o significado da formação naquele contexto específico e com o número de formações equivalentes naquele contexto (chamemos de variantes sinónimas) que o aprendente achar por bem enumerar. Por semana, o professor poderá ocupar-se com práticas deste tipo em duas sessões de duas horas cada, devendo o aluno produzir cinco fichas, de cada vez, como a ficha que se apresenta no final deste texto (veja-se o Anexo para também acompanhar o que se diz a seguir).

Tanto a resposta $\mathrm{B}$ como a resposta por meio da variante $\mathrm{V} 1$ existem no PE (Europeu), no PM (Moçambicano) e no PB (Brasileiro). De notar que em relação à $\mathrm{V} 1$, como resposta à pergunta feita em $\mathrm{A}$, a resposta ocorre em forma de uma interrogação. À medida que a curiosidade do aprendente aumenta, poderá mesmo interessar-se por equivalentes em outras variedades da língua portuguesa como, por exemplo, a variante que é específica e exclusiva ao PB:

Pergunta se macaco quer banana! (V2). Por outro lado, o aprendente poderá querer alargar o conhecimento de equivalentes noutras línguas como, por exemplo, no Inglês, que utiliza frequentemente na universidade moçambicana para ler e compreender a escrita:

V2' Is the Pope Catholic? [lit.: O Papa é católico?], ou

V2" Can snakes do push-ups? [lit.: As cobras conseguem fazer flexões?].

2 Idiomatismo bantu sugerido por Salvador Sitoe, a quem agradeço. 
Linha D'Água (Online), São Paulo, v. 31 , n. 1, p. 29-49 jan.-abril 2018

Trabalhar com fichas na sala de aulas é interessante, desenvolvendo-se diferentes rotinas que permitem ao aluno consolidar o seu conhecimento das formações idiomáticas escolhidas e partilhar, de forma mútua, a informação com os seus companheiros. Uma rotina simples consiste na criação de grupos de alunos trabalhando em pares, trocando entre si as fichas e testando-se uns aos outros. O aluno escolhe as formações idiomáticas com os seus respectivos contextos textuais (os cotextos). Nunca são os alunos que criam as formações. Estas práticas com as fichas são muito mais rigorosas e produtivas do que as buscas com o recurso ao dicionário, porque os potenciais significados são melhor activados através de contextos específicos; por outro lado, o tratamento da idiomaticidade, e da macrolinguística em geral, em dicionários é, normalmente, pobre ou inadequado e muitas vezes inexistente.

Vejamos esta prática comunicativa: num grupo de quatro, coloque uma barreira feita de cartão de modo a que dois alunos não consigam ver o que os outros dois estão a escrever usando uma formação idiomática. $O$ aluno número 1 escreve numa ficha um parágrafo em que conste, por exemplo, uma relação retórico-lógica de causa-efeito. Ao mesmo tempo, o aluno 3 escreve numa ficha um período em que conste, por exemplo, uma relação retórico-lógica de antecedência-consequência. Posto isso, o aluno 2 olha para o período do colega e instrui o aluno 3 a fazer algo idêntico, isto é, a escrever um período que contenha o mesmo tipo de relação causa-efeito. Por sua vez, o aluno 4 olha para o período que o colega escreveu à partida (envolve uma relação antecedência-consequência) e instrui o aluno 1 a escrever algo com esse tipo de relação.

De seguida, cada grupo vê o que o outro escreveu e discutem-se os quatro exemplos para os dois tipos de relações diferentes que cada grupo escolheu. Uma relação em que um evento (a causa) faz com que outro evento aconteça (o efeito), como, por exemplo, em: "Se a Judite não tivesse alarme, a casa teria sido assaltada." [Neste cenário, o alarme tem o efeito de impedir o assalto]; e a outra relação em que o antecedente constitui a primeira metade de uma proposição hipotética, e o consequente a segunda, como neste exemplo produzido por um aluno: "Se continuares a estudar apenas meia hora por dia, então é pouco provável que venhas a passar nesse exame, habitualmente difícil.” [Este é o cenário do se...então]. 
Linha D'Água (Online), São Paulo, v. 31, n. 1, p. 29-49 jan.-abril 2018

\section{Considerações finais}

O nosso objectivo foi analisar alguns fragmentos discursivos que considerámos infelizes. $\mathrm{O}$ argumento cingiu-se no seguinte: que, embora os aprendentes de nível avançado raramente cometam erros gramaticais e lexicais ao seu nível de aprendizagem da composição escrita, eles perpetuam, por vezes, infelicidades discursivas na língua-alvo, neste caso, a língua portuguesa. Por outras palavras, interessámo-nos por instâncias de discurso cuja gramática e léxico são nativos ou quase-nativos, mas em que a retórica e cognitividade na língua-alvo não foram processadas adequadamente.

O que o escrevente não-nativo (e, por vezes, mesmo o quase-nativo) tende a não realizar com total sucesso na comunicação são os rituais da escrita, por vezes, inadequadamente influenciada pela oralidade, assim como a progressão temática,

A [pergunta]: Hoje o dia está muito quente, meu amigo! Vai uma cervejinha à pressão?

B: [responde] Isso é lá pergunta que se faça!

incluindo o tipo de texto e o nível de idiomaticidade - ora por defeito, i.é, a nível sub-idiomático - por comparação com o escrevente nativo médio - ora, por excesso, i.é, a nível sobre-idiomático, talvez num esforço de não querer parecer muito monótono na escrita, sobregeneralizando formações idiomáticas de diverso tipo. Num contexto plurilingue e pluricultural, como o de Moçambique, as principais infelicidades - em termos da utilização cotextual [cotextual usage] do discurso e do seu uso contextual [contextual use] - produzidas pela interferência da língua nativa bantu são, em nosso julgamento, melhor acauteladas quando se implementa um ensino que tenha também como componente essencial a execução de Análises Contrastivas Discursivas explícitas. 
Linha D'Água (Online), São Paulo, v. 31, n. 1, p. 29-49 jan.-abril 2018

Quanto à abordagem alegórica que, por vezes, expressa a metáfora - por via da comparação, sátira, fábula, apólogo, ironia, mito - acompanhada de determinada moral e relacionando o sentido literal com o figurado, achamos que será melhor complementada por abordagens tautegóricas. Sobre a ideia fundamental em que a discussão metodológica se centra, somos de opinião que o aluno poderá estar em melhor posição para determinar as formações idiomáticas a serem adicionadas adequadamente ao mundo da idiomaticidade que já conhece e utiliza. Achamos que o enriquecimento idiomático do escrevente não ocorrerá necessariamente pelo facto do aluno recorrer com frequência ao dicionário que, na maior parte dos casos, é limitado no tratamento da idiomaticidade e, em regra, não ajuda no que toca à contextualização em que as diferentes categorias idiomáticas são utilizadas. Por analogia, e a propósito de uma avaliação de perspectivas conceptuais sobre a metáfora e a metonímia, adoptadas por diferentes linguistas, é interessante constatar que Campos e Chaves (2016) assumem que é relevante explicar conceitos, por meio de textos visuais, sem recorrer "ao serviço tradicional das gramáticas" (p. 208) e, assim, encurtar distâncias entre o aluno e o conteúdo.

\section{Referências}

AUSTIN, J. L. How to do things with words. Oxford: Clarendon Press, 1962.

CAMPOS, M.I.B. \& CHAVES, I. D. Entendendo o ensino da metáfora e da metonímia. In: MICHELETTI, G.; CAMPOS, M. I. B. (orgs.). Cadernos de linguística: pesquisa em movimento. Discurso, estilo, ensino: diferentes práticas de linguagem, São Paulo: Universidade Cruzeiro do Sul; Terracota, 2016, p. 191-211.

GOMANE, O. Mecanismos de estruturação informacional em textos 'expositivos/ explicativos'.

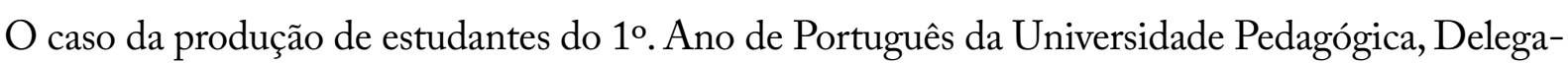
ção de Gaza, Moçambique. Tese (Doutorado), Universidade Eduardo Mondlane, Maputo, 2013.

KAPLAN, R.B. \& BALDAUF, Jr., R. B. (eds) Language planning in Malawi, Mozambique and the Philippines. Clevedon: Multilingual Matters, 1999. 
Linha D'Água (Online), São Paulo, v. 31, n. 1, p. 29-49 jan.-abril 2018

KITOKO-NSIKU, E. Mythos and wisdom in Genesis 3: 1-24 revisited from an African tautegorical view. CLÉ, Yaundé, Camarões, 2007.

LANGA, J. Uma abordagem interlinguística e intercultural à linguagem idiomática no discurso escrito em Português redigido por alunos universitários moçambicanos. Tese (Doutorado), Universidade Eduardo Mondlane, Maputo, 2017.

LOPES, A. J. A batalha das linguas: perspectivas sobre Linguistica Aplicada em Moçambique. Luanda: Editora das Letras. [original: Lopes, A. J. (2004) A batalha das linguas: perspectivas sobre Linguistica Aplicada em Moçambique/The Battle of the Languages: Perspectives on Applied Linguistics in Mozambique. Maputo: UEM], 2013.

Language revitalisation and reversal in Mozambique: The case of Xirhonga in Maputo. Current Issues in Language Planning [UK], 2001. p. 259-267.

The language situation in Mozambique. In: R. B. Kaplan \& R. B. Baldauf, Jr. eds, 1999. p. $86-132$.

Politica Linguística: Principios e Problemas/Language Policy: Principles and Problems. Maputo: Livraria Universitária, 1997.

Interlingual discourse transfer: Mozambican-Portuguese to English. Tese (Doutorado), University of Wales, UK, 1986.

MABASSO, E. \& LANGA, P. Com todos os efes e erres: para um Léxico de Usos Idiomáticos - Português-Inglês-Xichangana/With all the bells and whistles: towards a Lexicon of Idiomatic Usage - Portuguese-English-Shangaan/Kudlaya Nsuna ni Bawa: Ta Kukongoma marito Ya Kufambelana ni Kutirhisa Svivulavulelo-Xiputukezi-Xinghiza-Xichangani. Maputo: Livraria Universitária, 2016.

MARQUESI, S. C., ELIAS, V. M. \& CABRAL, A. L. T. Planos de texto, sequências textuais e orientação argumentativa. In S.C. Marquesi, A.L. Pauliukonis \& V.M. orgs, 2017, p. 13-32.

MARQUESI, S.C., PAULIUKONIS, A.L. \& ELIAS, V.M. Linguistica textual e ensino. São Paulo: Contexto, 2017.

MAVALE, C. A competência linguístico-discursiva de estudantes universitários Moçambicanos na produção do texto escrito argumentativo em língua portuguesa. Tese (Doutorado), University Eduardo Mondlane, Maputo, 2016.

LOPES, A. J. 0 aluno universitário moçambicano PL2 e os caminhos da escrita: um trilho seguro vale 
Linha D'Água (Online), São Paulo, v. 31 , n. 1, p. 29-49 jan.-abril 2018

MEDGYES, P. The Non-Native Teacher. Londres: Macmillan Publishers, 1994.

MICHELETI, G. \& CAMPOS, M. I. B. (orgs) Cadernos de linguistica: pesquisa em movimento. Discurso, estilo, ensino: diferentes práticas de linguagem. São Paulo: Terracota, vol 5, 1 ed. 2016.

SANTOS, M. dos. Learning languages on the web: issues of knowledge and verification. Dissertação (Mestrado), University of Queensland, Brisbane, Austrália, 2003.

TADROS, A. Prediction in text. Birmingham: University of Birmingham Publishers, 1985.

WIDDOWSON, H.G. Teaching language as communication. Oxford: Oxford University Press, 1978.

Recebido em 19/09/2017

Aprovado em 11/01/2018

LOPES, A. J. 0 aluno universitário moçambicano PL2 e os caminhos da escrita: um trilho seguro vale 
Linha D'Água (Online), São Paulo, v. 31 , n. 1, p. 29-49 jan.-abril 2018

\section{Anexo}

Figura 2. Parte da frente da ficha

Figura 3. Verso da ficha

Significado: trata-se de uma pergunta retórica que, por isso neste caso, não requer resposta; está calor e todos sabem que o interlocutor gosta muito da cerveja local; e se houver resposta significa que a pergunta requer uma resposta afirmativa óbvia; tratar-se, pois, de uma intervenção irónica! A pergunta é feita apenas para manter a idiomaticidade no discurso. $\mathrm{O}$ interlocutor insinua que a pergunta que ouviu era, no mínimo, desnecessária, pelo facto do contexto ser demasiado óbvio; não requer nenhuma resposta porque, em termos idiomáticos, essa não é a expectativa; se necessário, espera-se só um simples sim por parte do interlocutor.

\section{Variantes $(\mathrm{V})$ :}

V1 O que é que acha? 